\title{
Detection of Aflatoxin in Aspergillus Species Isolated from Immunocompromised Hospitalized Patients
}

\author{
Iman M.A. El kholy ${ }^{\#}$ and Sherin Ahmed Elmasry* \\ Microbiology Department and "Clinical Pathology Department, \\ Ain Shams University Specialized Hospital, Cairo, Egypt .
}

\begin{abstract}
A SPERGILLUS infections have grown in importance in the last few decades. However, most of the studies have focused on Aspergillus fumigatus, the most prevalent species in the human infections which is followed by Aspergillus flavus. Eventhough Aspergillus flavus was more common than A. fumigatus in some reports. Aspergillus niger came next to them causing invasive aspergillosis . Aspergillus flavus is a widely feared fungal pathogen capable of producing aflatoxin, the most potent mycotoxin . Two hundred and fifty hospitalized patients were studied for fungal infection. Out of the collected cases 109 were positive fungal infection representing $43.6 \%$ of the total cases. The age of the patients ranged from 22 to 68 years, of which $61 \%$ were male and $39 \%$ were female. Three species of the genus Aspergillus were collected from 18 cases representing $16.5 \%$ of the total positive. These isolates identified as Aspergillus flavus (11 cases ) followed by A .niger (5 cases) and A. fumigatus ( 2 cases ) representing $10.1 \%$, $4.6 \%$ and $1.8 \%$, respectively. Identification was carried out using the traditional method and confirmed by the molecular techniques (amplification of the internal transcribed spacer 2 (ITS2) region and direct sequencing followed by comparative GenBank analysis ). All the isolates were tested for aflatoxin production using High Performance Liquid Chromatography (HPLC). Aflatoxins B1 and B2 were produced from A. flavus only while A. niger and A. fumigatus were non- producers. Voriconazole $(200 \mathrm{mg} / 12 \mathrm{~h}$ for 12 weeks $)$ and Micafungin (100-150 mg/day for 12 weeks) were successfully used for treating all the cases.
\end{abstract}

Keywords: Aflatoxin, Aspergillus flavus, HPLC.

The genus Aspergillus includes over 200 species. So far around 20 species has been reported as causative agents of opportunistic infections in man (Dagenais \&Keller, 2009). A. fumigatus, A. flavus, A. parasiticus and A. niger are known to cause allergic reactions and are called allergic broncho pulmonary aspergillosis (ABPA) (Shankar et al., 2004). The most frequent species of Aspergillus causing invasive disease include $A$. fumigatus, A. flavus, A. niger, A. terreus, and rarely A. nidulans. The most common allergens include from $A$. fumigatus and $A$. clavatus. Other than A. fumigatus, the mold A. flavus also causes a broad spectrum of disease in human beings, ranging from hypersensitivity reactions to invasive

\#Corresponding author: imankholy@yahoo.com 
infection and has been considered second leading cause of aspergillosis (Denning, 1998 and Morgan et al., 2005). A. flavus is unique in being both plant and human pathogen. A. flavus and A. parasiticus are the major producers of mycotoxins (aflatoxins) that contaminant cereal grains such as groundnut, maize, etc., a leading to economic losses (Shankar et al., 2005). A person can inhale several hundred conidia of A. fumigatus per day (Latge, 1999). Although the spores of $A$. fumigatus are found in a small proportion of all the airborne spores within a hospital (approximately 0.3\%). Approximately 30\% to $90 \%$ of the systemic infections are due to Aspergillus (Brakhage \& Langfelder, 2002). A. fumigatus has gained importance because it easily causes infection in immunocompromised patients.

Human body temperature appears to provide the ideal condition for the development of invasive disease due to $A$. fumigatus and reducing the impact by other Aspergillus species such as A. flavus, and A. niger (Araujo \& Rodrigues, 2004). The most common clinical manifestation of infection by Aspergillus species is invasive aspergillosis with mortality higher than $90 \%$. A. fumigatus, A. flavus, A. niger and A. terreus are frequently isolated from airways (nose, throat, bronchi) of such patients, and colonization could lead to invasive aspergillosis (Kosalec \& Pepeljnjak, 2005). Aflatoxins (AFB1, AFB2, AFG1, AFG2, and AFM1) are mycotoxins produced by $A$. flavus, A. parasiticus and A. nomius strains. The production of the major toxins are a result of particular strains of A. flavus, B1 is the most common and most toxic (Hedayati et al., 2007). Aflatoxins also show a wide range of immunotoxic effects, they depress phagocytosis, intracellular killing and spontaneous superoxide production of macrophages (Cusumona et al., 1990 and Hinton et al., 2003). Aflatoxin B1 also inhibits the production of the tumor-necrosis factor (TNF), population interleukin-1 (IL1) and IL-6 by lipopolysaccharide-stimulated macrophages (Moon et al., 1999). This study aimed to study aflatoxin production from aspergilli isolated from immunocompromised hospitalized patients. In humans, A. flavus aflatoxin production can lead to acute hepatitis, immunosuppression, hepatocellular carcinoma, and neutropenia. It is highly possible for A. flavus to invade arteries of the lung or brain and cause infarction. The absence of any regulation of screening for the fungus in countries that also have a high prevalence of viral hepatitis highly increases the risk of hepatocellular carcinoma (Crawford, 2005).

Micafungin is a natural product derived from other fungi as a defense mechanism for competition of nutrients. Micafungin is produced by Coleophoma empetri (Hashimoto, 2009 and Fujie \& Akihiko, 2007) . Micafungin (trade name Mycamine) is an echinocandin antifungal drug. It inhibits the production of beta-1,3-glucan, an essential component of fungal cell walls . Micafungin is indicated for the treatment of candidiasis and other opportunistic mycosis (Pappas et al., 2007 ) . Voriconazole is a triazole antifungal medication that is generally seen in patients who are immmunocompromised, and include invasive candidiasis, invasive aspergillosis, and certain emerging fungal infections. Voiconazole has become the new standard of care in treatment of invasive aspergillosis .Voriconazole is more effective than other azole drugs in blocking sterol biosynthesis, consistent with the different antifungal potencies of these compounds (Smith et al., 2006 ) .

Egypt. J. Microbiol. 50 (2015) 
Study population

\section{Materials and Methods}

This study included 250 immunocompromised hospitalized patients at Ain Shams University Hospitals ( Ain Shams University ) during the year June 2012- May 2013. The microbiology laboratory records were reviewed daily. The corresponding medical records were reviewed and the clinical data analyzed included demographic characteristics, site of infection, host factors and the type of underlying disease at the time of diagnosis of the infection.

\section{Sampling, culturing and strain identification}

The collected sputum, urine, blood, bile, ascetic fluid, pleural fluid, pus, and throat swab samples were directly cultured on Sabouraud dextrose agar (SDA) and potato dextrose agar (PDA). The obtained isolates were identified through examination of micro- and macro-morphologic features in accordance with standard morphological criteria (Gonzalez et al., 2008; Ribes et al., 2000.; Madhavan et al., 2011; de Hoog et al., 2011 and Gomes et al., 2011). In addition to the traditional method of identification, molecular techniques were used by comparing the ITS1-5.8S-ITS2 rDNA region sequence data of the isolated strains with reference strains data deposited in GenBank.

\section{Extraction of DNA}

Fungal isolates were grown on PDA. DNA extracted from the fungal isolates mentioned was conducted in accordance with the instructions provided by Fermentas Genomic DNA Purification Kit \#K0512 (Thermo Fischer Scientific, EU). Briefly, a sufficient inoculum was suspended in $200 \mu \mathrm{TE}$ buffer $(10 \mathrm{mM}$ Tris-HCl, $\mathrm{pH} 8.0,1$ mM EDTA) in a $2.2 \mathrm{ml}$ Eppendorf tube, the tubes were boiled for $3 \mathrm{~min}$ and then placed in ice water for $10 \mathrm{~min}$. Lysis solution $(400 \mu \mathrm{l})$ was added, the tubes heated to $65^{\circ} \mathrm{C}$ for $30 \mathrm{~min}$ and then $600 \mu \mathrm{l}$ of chloroform were added and mixed carefully. The aqueous phase containing DNA was separated by centrifugation for $10 \mathrm{~min}$ at 12,000 $\mathrm{rpm}$ at $4^{\circ} \mathrm{C}$ and mixed with $800 \mu \mathrm{l}$ precipitation solution by several inversions at room temperature for $1 \mathrm{~min}$ each. The tubes were then centrifuged for $10 \mathrm{~min}$ at $12,000 \mathrm{rpm}$ at $4^{\circ} \mathrm{C}$. The DNA pellets were dissolved in $100 \mu \mathrm{l}$ of $1.2 \mathrm{M} \mathrm{NaCl}$ solution by gentle vortexing. Ice cold isopropanol $(500 \mu \mathrm{l})$ was added to the solution, the tubes were incubated for $15 \mathrm{~min}$ at $-20^{\circ} \mathrm{C}$ and then centrifuged for $10 \mathrm{~min}$ at $12,000 \mathrm{rpm}$ at $4^{\circ} \mathrm{C}$. The DNA pellet was washed with $1 \mathrm{ml}$ ice cold $70 \%$ ethanol, dried and re-suspended in sterile TE buffer.

\section{Oligonucleotides}

The oligonucleotide primers used for amplification and sequencing of the ITS regions were those described by White et al., (1990). This study used ITS5 (5 GGAAGTAAA AGTCGTAACAAGG-3) and ITS4 (5 -TCCTCCGCTTATTGATATGC-3) (Bioneer Corporation, South Korea). PCR and DNA sequencing of ITS1- 5.8S- ITS2 region rDNA of fungal species.

Amplification reactions were performed in $20 \mu \mathrm{l}$ reaction mixture containing $2.5 \mu \mathrm{l}$ of each primer (10 pm), $2.5 \mu \mathrm{l}$ of genomic DNA $(5 \mu \mathrm{g} / \mathrm{ml})$, and one PCR-Gold MasterMix bead (Bioron-Germany; buffers, dNTP, enzyme, stabilizers, Tris- $\mathrm{HCl}, \mathrm{KCl}$, and 
$\mathrm{MgCl}_{2}$ ). Amplification was performed with a PCR Thermal Cycler (Techne Genius UK) using the initial denaturation at $96^{\circ} \mathrm{C}$ for $5 \mathrm{~min}, 35$ cycles of denaturation at $94^{\circ} \mathrm{C}$ for $30 \mathrm{sec}$, annealing at $52^{\circ} \mathrm{C}$ for $30 \mathrm{sec}$, extension at $72^{\circ} \mathrm{C}$ for $80 \mathrm{sec}$, and a final extension at $72^{\circ} \mathrm{C}$ for $10 \mathrm{~min}$. The PCR reaction products were sequenced directly using a Big-Dye terminator reagent kit including Taq polymerase and the protocol recommended by the manufacturer (Model 3100 automated DNA sequencer; PerkinElmer Inc./ Applied Biosystems - Bioneer, South Korea).

\section{Aflatoxin production}

All the Aspergillus isolates were tested for the production of aflatoxin based on the HPLC (Frisvad \& Thrane, 1993). The analytical standards (aflatoxins B1\& B2) was purchased from Sigma (St. Louis, MO), and a stock solution was prepared in acetonitrile/methanol (1:1) and stored in an amber vial in a freezer (ca-18C). Malt extract (MEA), liquid medium, was used for obtaining culture filtrate that is used in studying aflatoxin production by fungal tested strains.

\section{High performance thin layer chromatography (HPLC)}

After 14 days of incubation, the mate and the filtrate were defatted with n-hexane extracted using chloroform. The chloroform layer was collected then evaporated and concentrated then re- dissolved in $1 \mathrm{ml}$ chloroform.

Twenty microliters of the extracted samples were applied to HPLC plates $(20 \mathrm{~cm}$ x20 cm, silica gel 60 precoated plate, Merck Darmstadt, Germany) and developed with a 5:4:1 $(\mathrm{v} / \mathrm{v} / \mathrm{v})$ mixture of toluene: ethyl acetate : formic acid for $17 \mathrm{~cm}$ then scanned using CAMMAG TLC scanner system at the Regional Centre for Mycology and Biotechnology, Al-Azhar University, Cairo, Egypt. Aflatoxin analogues were detected as a bluish spot under UV-A $(365 \mathrm{~nm})$ illumination and were compared with authentic standard as well as griseofulvin (Frisvad \& Thrane, 1993).

\section{Results}

\section{Identification of isolates}

Out of 250 hospitalized patients included in this study, they were categorized according to their underlying diseases (Table 1). Of the collected samples, a total of 109 cases $(43.6 \%)$ were positive for fungal infection while 141(56.4\%) were considered negative. The highest number of patients positive for fungal infections were diabetes mellitus and chronic pulmonary disease patients (25 cases) and the least number of positive fungal infections were among liver cell failure (LCF) patients (2 cases) (Fig. 1). The recorded positive percentages among the studied patients showed high significance $(P$ value $<0.001)$.

Three species of Aspergillus were recovered (16.5\%) (Fig. 2). Aspergillus flavus was the most frequently recovered since it was isolated from 11 cases (10.1\%) followed by Aspergillus niger 5 cases which represented (4.6\%) while Aspergillus fumigatus was isolated from 2 cases representing (1.8\%). Concerning the site of infection 9 cases of Aspergillus were recovered from pulmonary infection, 7 cases renal infection and 2 cases cutaneous infection (Tables 2, 3).

Egypt. J. Microbiol. 50 (2015) 
TABLE 1. Frequency of fungal diseases among the study population .

\begin{tabular}{|l|c|c|c|}
\hline \multicolumn{1}{|c|}{ Underlying Diseases } & Total & Positive & Negative \\
\hline D M \&COPD & 84 & 25 & 59 \\
\hline Hematological malignancy & 45 & 22 & 23 \\
\hline D. Foot & 30 & 6 & 24 \\
\hline RF & 26 & 15 & 11 \\
\hline Solid organ transplantation & 16 & 14 & 2 \\
\hline Bronchogenic carcinoma & 16 & 13 & 3 \\
\hline Lymphoma & 16 & 7 & 9 \\
\hline Chronic-granulomatous disease & 11 & 5 & 6 \\
\hline LCF & 6 & 2 & 4 \\
\hline Total & $\mathbf{2 5 0}$ & $\mathbf{1 0 9}$ & $\mathbf{1 4 1}$ \\
\hline
\end{tabular}

D M: Diabetes mellitus, COPD: Chronic obstructive pulmonary disease., RF: Renal failure; LCF: Liver cell failure; DF: Diabetic foot.

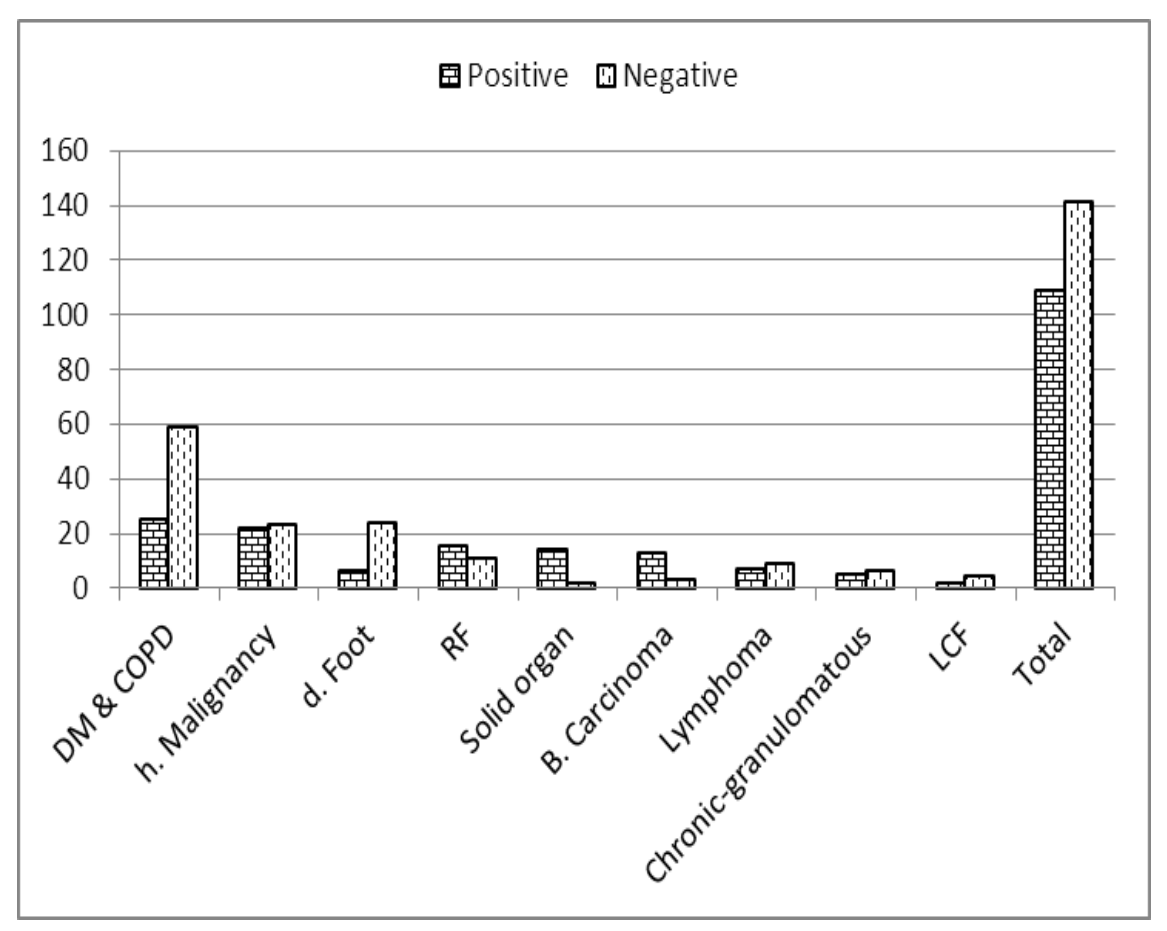

Fig. 1. Frequency of fungal diseases among the population study . 
QYeast and yeast like group (77\%)

Aspergillus group (16\%)

DFusarium group (4\%)

口Zygomycetes (3\%)

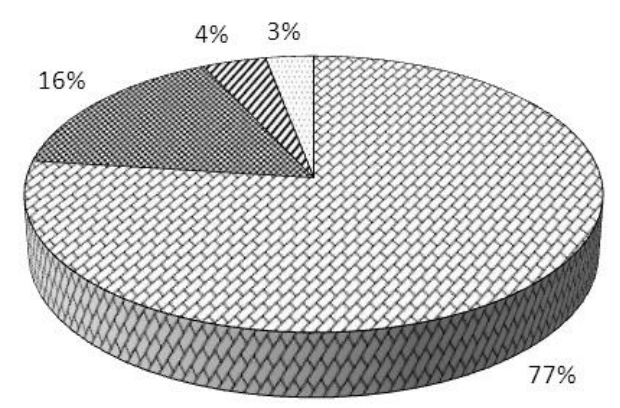

Fig. 2. Etiologic groups recovered from positive cases.

TABLE 2. Frequency of aspergillosis respective to infection sites.

\begin{tabular}{|c|c|c|c|c|c|c|c|}
\hline \multirow[t]{2}{*}{ No } & \multirow{2}{*}{ Etiologic agent } & \multicolumn{4}{|c|}{ Clinical presentation } & \multirow{2}{*}{ Total } & \multirow{2}{*}{$\%$} \\
\hline & & Pulmonary & Renal & Disseminated & Cutaneous & & \\
\hline 1 & Aspergillus flavus & 4 & 5 & - & 2 & 11 & 10.1 \\
\hline 2 & Aspergillus niger & 4 & 1 & - & - & 5 & 4.6 \\
\hline 3 & Aspergillus fumigatus & 1 & 1 & - & - & 2 & 1.8 \\
\hline Total & & 9 & 7 & - & 2 & 18 & \\
\hline
\end{tabular}

TABLE 3. Frequency of aspergillosis respective to underlying condition.

\begin{tabular}{|l|c|c|c|c|}
\hline \multirow{2}{*}{ Underlying Diseases } & \multicolumn{2}{c|}{ Etiologic agent } & \multirow{2}{*}{ Total } \\
\cline { 2 - 4 } & A. flavus & A. niger & A.fumigatus & \\
\hline D M \&COPD & 2 & 2 & - & 4 \\
\hline Hematological malignancy & 3 & - & - & 3 \\
\hline D. Foot & 2 & - & - & 2 \\
\hline RF & - & - & 1 & 1 \\
\hline Solid organ transplantation & 1 & - & - & 1 \\
\hline Bronchogenic carcinoma & 2 & 2 & - & 4 \\
\hline Lymphoma & - & 1 & 1 & 2 \\
\hline Chronic-granulomatous disease & - & - & - & - \\
\hline LCF & 1 & - & - & 1 \\
\hline Total & $\mathbf{1 1}$ & $\mathbf{5}$ & $\mathbf{2}$ & $\mathbf{1 8}$ \\
\hline
\end{tabular}

Egypt. J. Microbiol. 50 (2015) 
Molecular identification of the recovered isolates based on the sequence of the ITS1- 5.8S-ITS2 ribosomal DNA region revealed that the Aspergillus flavus was highly identical (>99\%) to the reference strain Aspergillus flavus (GenBank Accession No. JX028197) and the pair wise alignment between the recovered strain and the reference strain through blast homology search on gen bank database (NCBI) is shown in Fig. 3.

CLUSTAL W (1.83) multiple DNA sequence alignment

\begin{tabular}{|c|c|}
\hline A. flavus recovered & $\begin{array}{l}\text { CTCCCCCCGTGTTTACTGTACCTTAGTTGCTTCGGCGGGCCCGCCATTCATG } \\
\text { GCCGCCGG }\end{array}$ \\
\hline \multirow[t]{2}{*}{ A. flavus reference } & $\begin{array}{l}\text { CTCCCCCCGTGTTTACTGTACCTTAGTTGCTTCGGCGGGCCCGCCATTCATGGC } \\
\text { CGCCGG }\end{array}$ \\
\hline & 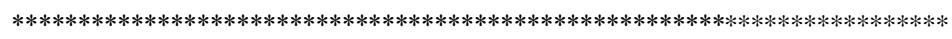 \\
\hline A. flavus recovered & $\begin{array}{l}\text { GGGCTCTCAGCCCCGGGCCCGCGCCCGCCGGAGACACCACGAACTCTGT } \\
\text { CTGATCTAGTG }\end{array}$ \\
\hline A. flavus reference & $\begin{array}{l}\text { GGGCTCTCAGCCCCGGGCCCGCGCCCGCCGGAGACACCACGAACTCT } \\
\text { GTCTGATCTAGTG } \\
* * * * * * * * * * * * * * * * * * * * * * * * * * * * * * * * * * * * * * * * * * * * * * * * * * * * * * * * * * * * * * *\end{array}$ \\
\hline A. flavus recovered & $\begin{array}{l}\text { AAGTCTGAGTTGATTGTATCGCAATCAGTTAAAACTTTCAACAATGGATCT } \\
\text { CTTGGTTCC }\end{array}$ \\
\hline A. flavus reference & $\begin{array}{l}\text { AAGTCTGAGTTGATTGTATCGCAATCAGTTAAAACTTTCAACAATGGATCTCTTGG } \\
T T C C \\
* * * * * * * * * * * * * * * * * * * * * * * * * * * * * * * * * * * * * * * * * * * * * * * * * * * * * * * * * * * * * * * * * * * * * * * *\end{array}$ \\
\hline A. flavus recovered & $\begin{array}{l}\text { GGCATCGATGAAGAACGCAGCGAAATGCGATAACTAGTGTGAATTGCAGA } \\
\text { ATTCCGTGAA }\end{array}$ \\
\hline A. flavus reference & $\begin{array}{l}\text { GGCATCGATGAAGAACGCAGCGAAATGCGATAACTAGTGTGAATTGCA } \\
\text { GAATTCCGTGAA } \\
\text { ****************************************************************** }\end{array}$ \\
\hline A. flavus recovered & $\begin{array}{l}\text { TCATCGAGTCTTTGAACGCACATTGCGCCCCCTGGTATTCCGGGGGGCATG } \\
\text { CCTGTCCGA }\end{array}$ \\
\hline A. flavus reference & 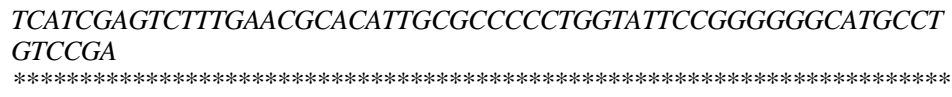 \\
\hline A. flavus recovered & $\begin{array}{l}\text { GCGTCATTGCTGCCCATCAAGCACGGCTTGTGTGTTGGGTCGTCGTCCCCTCTC } \\
\text { CGGGGG }\end{array}$ \\
\hline A. flavus reference & $\begin{array}{l}\text { GCGTCATTGCTGCCCATCAAGCACGGCTTGTGTGTTGGGTCGTCGTCCCCTCTC } \\
C G G G G G \\
* * * * * * * * * * * * * * * * * * * * * * * * * * * * * * * * * * * * * * * * * * * * * * * * * * * * * * * * * * * * * * * * * * * * * * *\end{array}$ \\
\hline A. flavus recovered & $\begin{array}{l}\text { GGACGGGCCCCAAAGGCAGCGGCGGCACCGCGTCCGATCCTCGAGCGTAT } \\
\text { GGGGCTTTGT }\end{array}$ \\
\hline A. flavus reference & $\begin{array}{l}\text { GGACGGGCCCCAAAGGCAGCGGCGGCACCGCGTCCGATCCTCGAGCGTATGG } \\
G G C T T T G T \\
* * * * * * * * * * * * * * * * * * * * * * * * * * * * * * * * * * * * * * * * * * * * * * * * * * * * * * * * * * * * * * * * * * * * * * *\end{array}$ \\
\hline A. flavus recovered & $\begin{array}{l}\text { CACCCGCTCTGTAGGCCCGGCCGGCGCTTGCCGAACGCAAATCAATCTT } \\
\text { TTTCCAGGTTG }\end{array}$ \\
\hline A. flavus reference & $\begin{array}{l}\text { CACCCGCTCTGTAGGCCCGGCCGGCGCTTGCCGAACGCAAATCAATCTTTTTCC } \\
\text { AGGTTG } \\
* * * * * * * * * * * * * * * * * * * * * * * * * * * * * * * * * * * * * * * * * * * * * * * * * * * * * * * * * * * * * * * * * * * *\end{array}$ \\
\hline A. flavus recovered & АCСТCGGATCAGGTAGGGATACCCGCTGAACTTAAGCATATCAATAA \\
\hline A. flavus reference & 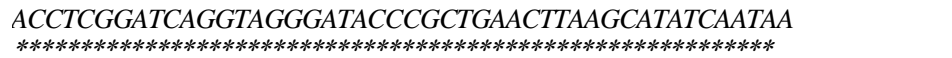 \\
\hline
\end{tabular}

Fig. 3. Interspecific alignments of the 5.8S ribosomal DNA and the flanking internal transcriped spacers (ITS1 and ITS2) of Aspergillus flavus (GenBank Accession No.JX028197) and recovered Aspergillus flavus strain. 
Aspergillus niger was highly identical (>99\%) to reference strain Aspergillus niger (GenBank Accession No.KF358715) and the pair wise alignment between the recovered strain and the reference strain through blast homology search on gen bank database (NCBI) is shown in Fig. 4.

CLUSTAL W (1.83) multiple DNA sequence alignment

\begin{tabular}{|c|c|}
\hline A.niger recovered & AGTGCGGGTCCTTTGGGACCCAACCTC \\
\hline A.niger reference & $\begin{array}{l}\text { AGTGCGGGTCCTTTGGGACCCAACCTC } \\
* * * * * * * * * * * * * * * * * * * * * * * * * * * * * * * *\end{array}$ \\
\hline A.niger recovered & $\begin{array}{l}\text { CCATCCGTGTCTATTGTACCCTGTTGCTTCGGCGGGCCCGCCGCTTGTCGGC } \\
C G C C G G G G\end{array}$ \\
\hline A.niger reference & $\begin{array}{l}\text { CCATCCGTGTCTATTGTACCCTGTTGCTTCGGCGGGCCCGCCGCTTGTCG } \\
G C C G C C G G G G \\
* * * * * * * * * * * * * * * * * * * * * * * * * * * * * * * * * * * * * * * * * * * * * * * * * * * * * * * * * * * * * *\end{array}$ \\
\hline A.niger recovered & $\begin{array}{l}\text { GGGCGCCTCTGCCCCCCGGGCCCGTGCCCGCCGGAGACCCCAACACGA } \\
\text { АCACTGTCTGAA } \\
\text { *************************************************************** }\end{array}$ \\
\hline A.niger reference & $\begin{array}{l}\text { GGCATCGATGAAGAACGCAGCGAAATGCGATAACTAGTGTGAATTGCA } \\
\text { GAATTCCGTGAA }\end{array}$ \\
\hline A.niger recovered & $\begin{array}{l}\text { AGCGTGCAGTCTGAGTTGATTGAATGCAATCAGTTAAAACTTTCAACAATG } \\
\text { GATCTCTTG }\end{array}$ \\
\hline A.niger reference & $\begin{array}{l}\text { AGCGTGCAGTCTGAGTTGATTGAATGCAATCAGTTAAAACTTTCAACAATG } \\
G A T C T C T T G \\
* * * * * * * * * * * * * * * * * * * * * * * * * * * * * * * * * * * * * * * * * * * * * * * * * * * * * * * * * * *\end{array}$ \\
\hline A.niger recovered & $\begin{array}{l}\text { GTTCCGGCATCGATGAAGAACGCAGCGAAATGCGATAACTAATGTGAATT } \\
\text { GCAGAATTCA }\end{array}$ \\
\hline A.niger reference & $\begin{array}{l}\text { GTTCCGGCATCGATGAAGAACGCAGCGAAATGCGATAACTAATGTGAATT } \\
\text { GCAGAATTCA } \\
* * * * * * * * * * * * * * * * * * * * * * * * * * * * * * * * * * * * * * * * * * * * * * * * * * * * * * * * * * * * * * * *\end{array}$ \\
\hline A.niger recovered & $\begin{array}{l}\text { GTGAATCATCGAGTCTTTGAACGCACATTGCGCCCCCTGGTATTCCGGGG } \\
\text { GGCATGCCTG }\end{array}$ \\
\hline A.niger reference & $\begin{array}{l}\text { GTGAATCATCGAGTCTTTGAACGCACATTGCGCCCCCTGGTATTCCGGGG } \\
G G C A T G C C T G \\
* * * * * * * * * * * * * * * * * * * * * * * * * * * * * * * * * * * * * * * * * * * * * * * * * * * * * * * * * * * * * * *\end{array}$ \\
\hline A.niger recovered & $\begin{array}{l}\text { TCCGAGCGTCATTGCTGCCCTCAAGCCCGGCTTGTGTGTTGGGTCGCCG } \\
\text { TCССССТCТCC }\end{array}$ \\
\hline A.niger reference & $\begin{array}{l}\text { TCCGAGCGTCATTGCTGCCCTCAAGCCCGGCTTGTGTGTTGGGTCGCCG } \\
\text { TCCСCСТCTCC } \\
* * * * * * * * * * * * * * * * * * * * * * * * * * * * * * * * * * * * * * * * * * * * * * * * * * * * * * * * * * * * * *\end{array}$ \\
\hline A.niger recovered & 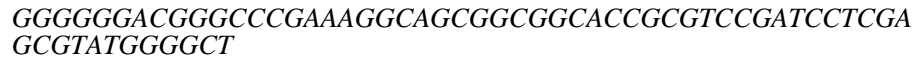 \\
\hline A.niger reference & 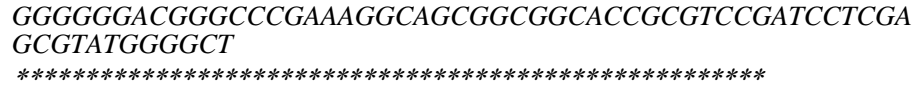 \\
\hline $\begin{array}{l}\text { A.niger recovered } \\
\text { A.niger reference }\end{array}$ & $\begin{array}{l}\text { TTGTCACATGCTCTGTAGG } \\
\text { TTGTCACATGCTCTGTA } \\
* * * * * * * * * * * * * * * * * * *\end{array}$ \\
\hline
\end{tabular}

Fig. 4. Interspecific alignments of the 5.8S ribosomal DNA and the flanking internal transcriped spacers (ITS1 and ITS2) of Aspergillus niger (GenBank Accession No.KF358715) and recovered Aspergillus niger strain .

Egypt. J. Microbiol. 50 (2015) 
Aspergillus fumigatus was highly identical (>99\%) to reference strain Aspergillus fumigatus (GenBank Accession No. KF201647) and the pair wise alignment between the recovered strain and the reference strain through blast homology search on gen bank database (NCBI) is shown in Fig. 5.

CLUSTAL W (1.83) multiple DNA sequence alignment

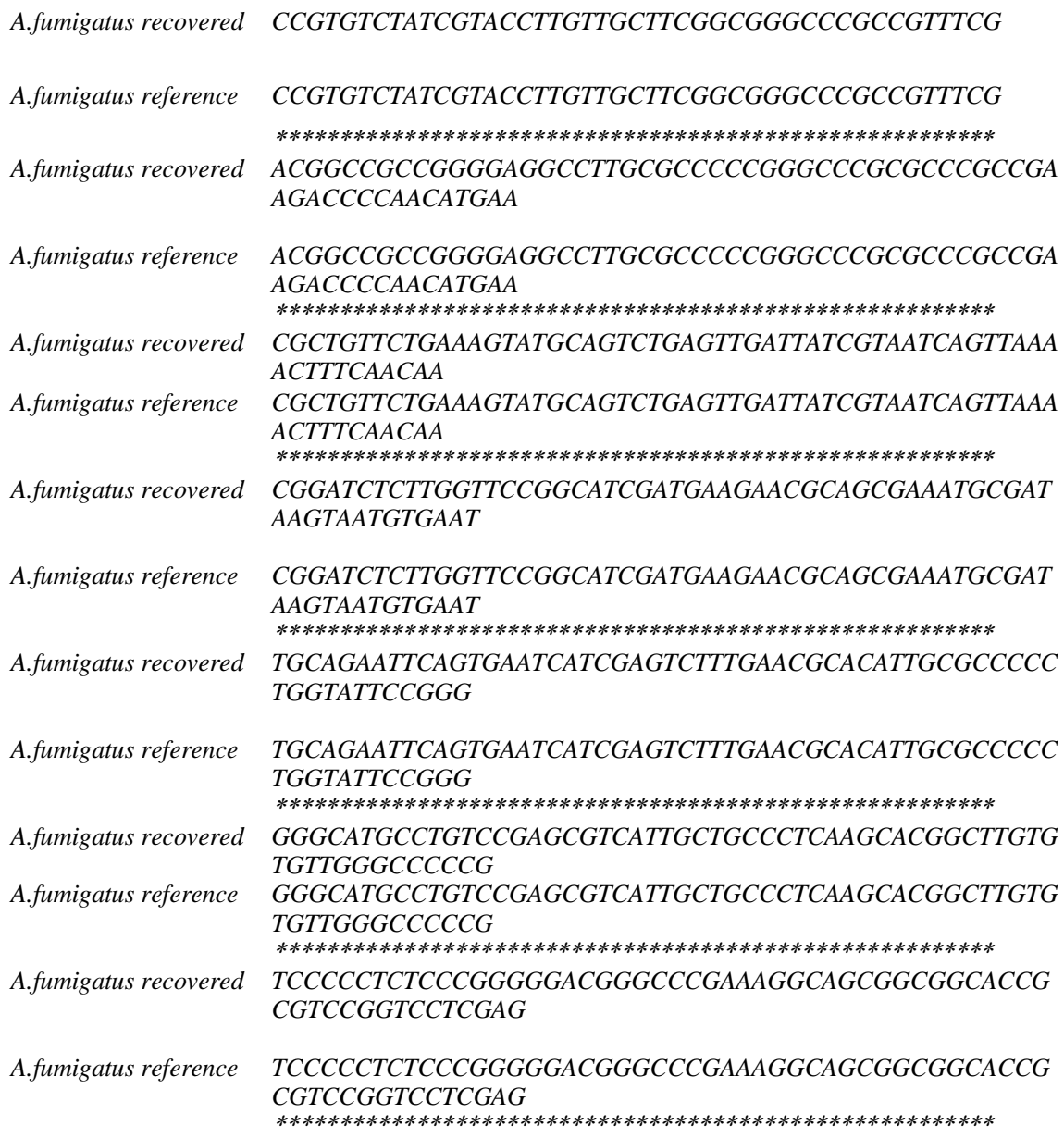

A.fumigatus reference TCCCCCTCTCCCGGGGGACGGGCCCGAAAGGCAGCGGCGGCACCG CGTCCGGTCCTCGAG

A.fumigatus recovered CGTATGGGGCTTTGTCACCTGCTCTGTAGGCCCGGCCGGCGCC

A.fumigatus reference CGTATGGGGCTTTGTCACCTGCTCTGTAGGCCCGGCCGGCGCC

Fig. 5. Interspecific alignments of the 5.8S ribosomal DNA and the flanking internal transcriped spacers (ITS1 and ITS2) of Aspergillus fumigatus (GenBank Accession No.KF201647) and recovered Aspergillus fumigatus strain. 
Aflatoxin analysis

Among the 18 isolates of Aspergillus tested for aflatoxin production by HPLC method, A. flavus isolates were the aflatoxin producers, while A. niger and A. fumigatus were non producers (Fig. 6,7). The result of scoring the intensity of the bands on HPLC plates revealed that all aflatoxinogenic isolates were able to yield aflatoxins B1 and B2.

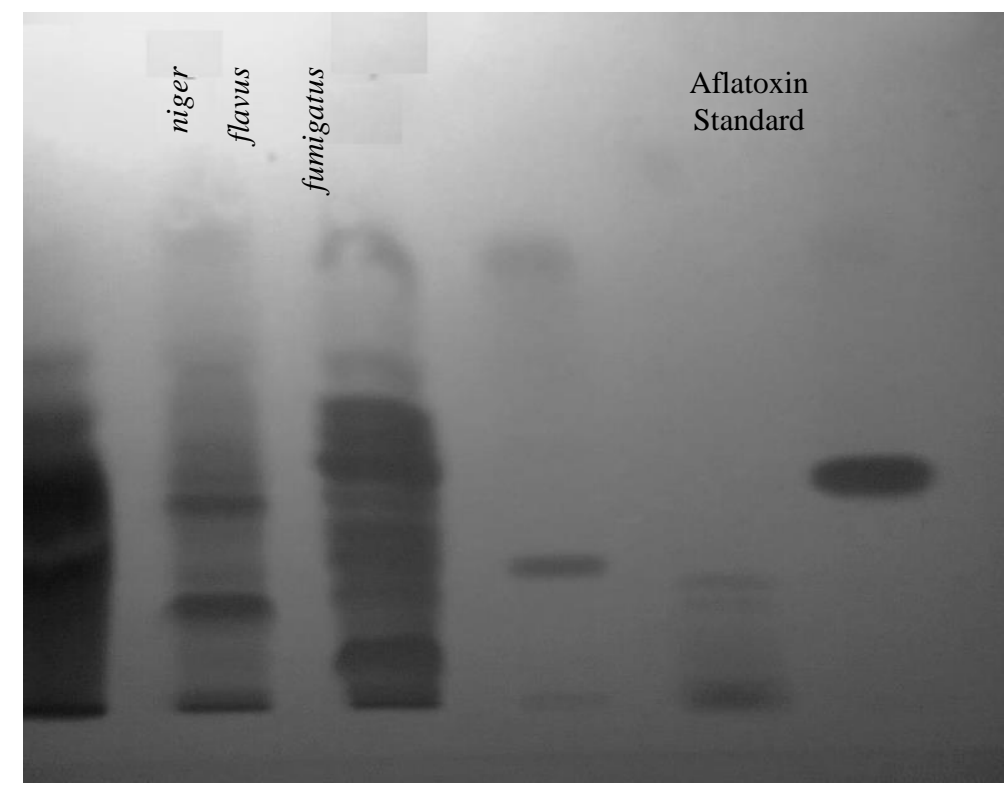

Fig. 6. Blue fluorescence aflatoxins B1and B2 produced by Aspergillus flavus while A.niger and A. fumigatus are negative by HPLC.

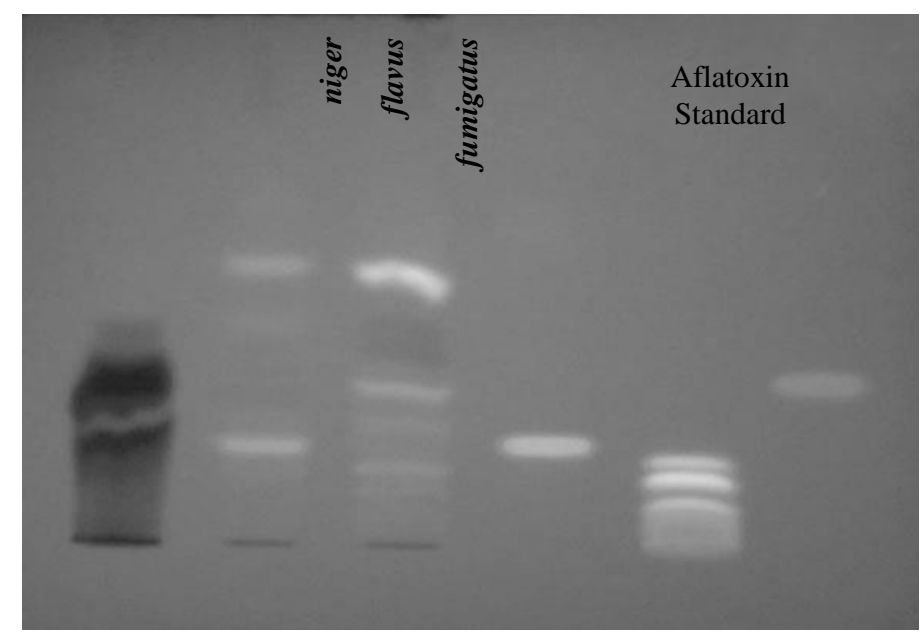

Fig. 7. HPLC analysis of aflatoxins production B1, B 2 of Aspergillus flavus with aflatoxin standard.

Egypt. J. Microbiol. 50 (2015) 


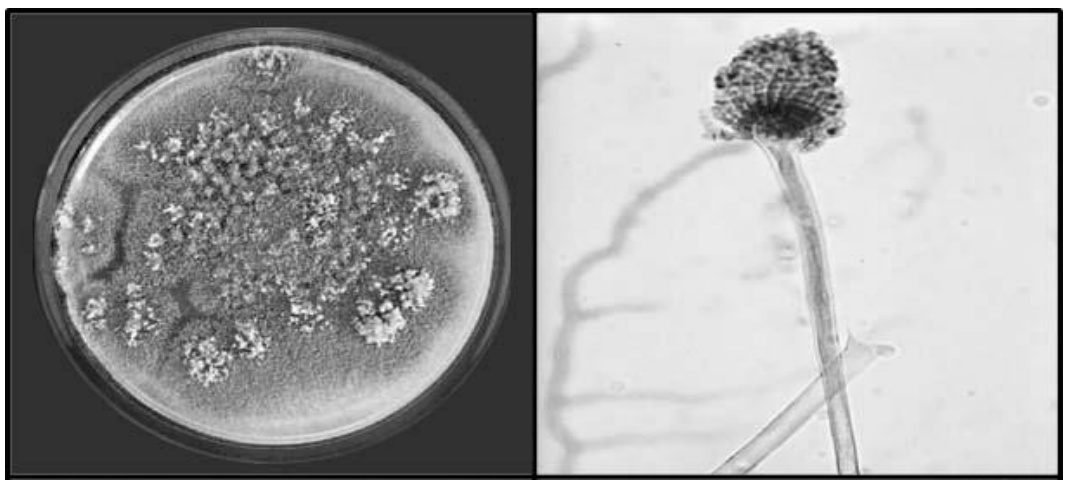

Photo

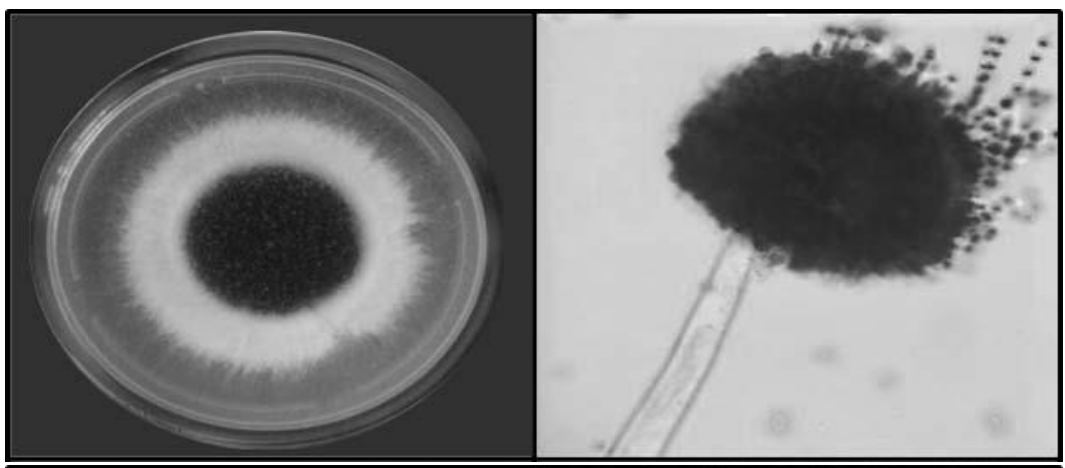

Photo

(1B)

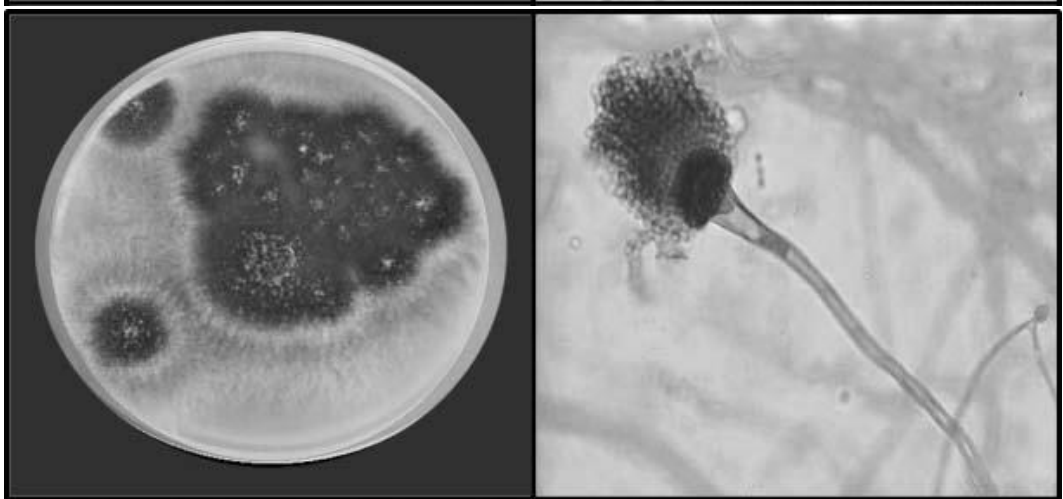

Photo

(1C)

Photo 1A. Macroscopic and microscopic characteristics of Aspergillus flavus. Yellowishgreen colony, radiate conidial heads, conidiogenous cells are uni and bi-seriate. Conidiophores are rough-walled, hyaline. Vesicles are spherical, conidia echinulate and spherical.

Photo 1B. Macroscopic and microscopic characteristics of Aspergillus niger. Black colony, radiate conidial heads, conidiophores are smooth-walled, hyaline or pigmented. Vesicles are sub spherical, conidiogenous cells are bi-seriate, metulae are twice as long as the phialides. Conidia are brown, ornamented with warts.

Photo 1C. Macroscopic and microscopic characteristics of Aspergillus fumigatus. Dark blue-green colony, columnar conidial heads, conidiophores are smooth-walled. Vesicles are sub clavate conidiogenous cells are uni-seriate. Conidia are verrucose and subspherical. 


\section{Treatment and outcome}

All the diagnosed patients with aspergillosis in this study received specific therapy of antifungal as Micafungin in patients infected with yeast and yeast like fungi (100-150 mg/day for 12 weeks) and Voriconazole in patients infected with Aspergillus species $(200 \mathrm{mg} / 12 \mathrm{~h}$ for 12 weeks). The median daily dose of Micafungin was 100-150/day and Voriconazole $200 \mathrm{mg} / 12 \mathrm{~h}$, and the median duration of treatment was 41 days (range, 35-49 days).

\section{Discussion}

Weakening of specific immunological and non-specific host defences may predispose Aspergillus infections in debilitated and immunocompromised patients in hospitals (Kothary et al., 1984 and Bondy\& Pestlea, 2000). One hundred and nine cases (43.6\%) were positive fungal infection out of 250 immunocompromised patients diagnosed in the present study. Multiple risk factors in patients of this study were, D M \& COPD (33.6\%), chronic granulomatous disease $(4.5 \%)$, LCF $(2.3 \%)$, RF (10.4\%), Solid organ transplantation (6.3\%), Bronchogenic carcinoma (6.3\%), Lymphoma (6.3\%), haematological malignancies (18.1\%), and diabetic foot (11.8\%) which is in line with Meersseman et al.( 2004), Vandewoude et al. (2006) and Prakash et al. (2014). Prakash et al. (2014) documented 17 positive cases of Aspergillus spp. out of 103 immunocompromised and 7 immunocompetent cases. Based on the data of the clinical history of their study, the various risk factors like pulmonary tuberculosis (9 of 33), diabetes mellitus ( 1 of 21), HIV infection (1 of 4), chronic smoking (4 of 42), bronchogenic carcinoma (3 of 6), bronchial asthma (3 of 15), pleural effusion (0 of 24), environmental exposure to asbestos, cement and other chemicals ( 2 of 22) and non significant factors ( 1 of 31$)$. In this study 18 positive cases of Aspergillus spp among 250 immunocompromised patients as various risk factors like COPD and D. M (4 of 84), solid organ transplantation (1 of 16), bronchogenic carcinoma (4 of 16), haematological malignancies (3 of 45), lymphoma (2 of 16), chronic granulomatous disease (0 of 11), R F (1 of 26), LCF (1 of 6) and diabetic foot ( 2 of 30$)$. In the present study three species of Aspergillus were identified (16\%), Aspergillus flavus was the most frequently recovered since it was isolated from 11 cases (10.4\%) followed by Aspergillus niger from 5 cases (4.2\%) and Aspergillus fumigatus was isolated from 2 cases (2.1\%). Carpagnano et al. (2014) confirmed 5 cases (11.6\%) of A. niger and 3 cases $(6 \%)$ of A.ochraceus out of 43 lung cancer patients while the present results showed that, 2 cases (1.8\%) of A. flavus and 2 cases (1.8\%) of A. niger were isolated from 16 bronchogenic carcinoma patients. Aspergillus species were isolated from 24 cases (23.3\%) out of 103 studied immunocompromised hospitalized patients,. Aspergillus fumigatus was the predominant species isolated from 13 cases (54.16\%) followed by Aspergillus flavus from 7 cases (29.16\%), Aspergillus niger from 3 cases (12.5\%) and Aspergillus terreus from 1 case $(4.16 \%)$. The results of this study revealed that the prevalence of pulmonary aspergillosis was $8.2 \%$ while others reported 8\% (Pepy et al., 1959), 8.2 (Campbell\& Clayton, 1964), 11\% (Henderson et al., 1968) and 23.3\% (Prakash et al., 2014). Haq et al. (2007) described a case of localized renal aspergillosis in

Egypt. J. Microbiol. 50 (2015) 
diabetic patients, Washawasky et al. (1975) and Godec et al. (1989) reported few cases of renal aspergillosis, while 7 cases were reported in the present study. Urinary tract aspergillosis due to A. flavus is rare with few reported cases (Khan et al., 1995; Perez-Arellano et al., 2001 and Kueter et al., 2002) as we isolated 5 cases of A. falvus in this study.

Aflatoxins are secondary metabolites produced namely by members of the Aspergillus flavus and A. parasiticus (Hedayati et al., 2007), and they cause diseases in poultry and domestic animals (Bondy \& Pestlea, 2000). However, little is known about production of aflatoxins by clinical isolates of A. flavus (strains isolated from immunocompromised patients). Shanker (2013) reported that $A$. flavus and A. fumigatus produce gliotoxin and aflatoxin in vivo, allow invasion in the host and they are involved in immunosuppression of the host contributing to pathogenesis. Kosalec \& Pepeljnjak (2005) detected aflatoxin B1 in 7 cases $(23 \%)$ and aflatoxin G1 in one case $(3 \%)$ out of 30 clinical isolates of A. flavus collected from immunocompromised patients in a haematological unit. Also they detected aflatoxins B1 and G1 in 11 cases (37\%) and one case (3\%) out of 30 environmental isolates of $A$. flavus. Considering this, in the present study $A$. flavus produced aflatoxins B1 and B2 while isolates of A. niger and A. fumigatus were not producers of aflatoxins. In recent years treatment with Voriconazole controlled aspergillosis in immunosuppressed patients (Patterson et la., 2005 and Agarwal \& Singh, 2006). In this study the 18 cases with Aspergillus infection were successfuly treated with Voriconazole. Herbrecht et al. (2002) reported that Voriconazole proved superior to Amphotercin B with 53\% complete or partial response, compared with $32 \%$ for Amphotercin B .

\section{Conclusion}

In this study Aspergillus flavus was the most frequent Aspergillus spp. causing human infections. The importance of this fungus increases in regions with a dry and hot climate. A. flavus isolates produce aflatoxins, the most potent hepatocarcinogenic natural toxin. In this study the in vitro production of toxic secondary metabolites - aflatoxins from the collected isolates of Aspergillus spp. isolated from immunocompromised patients was investigated. Results of aflatoxin production, including aflatoxin B1 and B2, was produced by A. flavus isolates only. In conclusion, the incidence of Aspergillus flavus was relatively high in this study and proved its ability of afaltoxin production. More investigations are needed to clear the role of aflatoxin in pathogenesis. Voriconazole proved its efficacy in treating the aspergillosis cases in this study .

Acknowledgement: I would like to thank the physicians of Ain Shams University Hospitals for their support and assistance in collecting work samples.

\section{References}

Agarwal, R. and Singh, N. (2006) Amphotericin B is still the drug of choice for invasive aspergillosis. Voriconazole versus amphotericin B for primary therapy of invasive aspergillosis. Am. J. Respir. Crit. Care Med. 174 (1),102.

Egypt. J. Microbiol. 50 (2015) 
Araujo, R. and Rodrigues, A.G. (2004) Variability of germinative potential among pathogenic species of Aspergillus. J. Clin. Microbiol., 42, 4335-4337.

Bondy, G.S. and Pestlea, J.J. ( 2000) Immunomodulation by fungal toxin. J. Toxicol. Envirn. Health B Crit Rev. 3, 109-43.

Brakhage, A.A. and Langfelder, K. (2002) Menacing mold: The molecular biology of Aspergillus fumigatus. Annu. Rev. Microbiol. 56, 433-455.

Campbell, M.J. and Clayton, Y.M. (1964) Bronchopulmonary aspergillosis. Am Rev Resp Dis. 89,186-195.

Carpagnano, E.G., Lacedonia, D., Palladino, G.P., Logrieco, G., Crisetti, E., Susca, A., Logrieco, A. and Foschino-Barbaro, M.P. (2014) Aspergillus spp. colonization in exhaled breath condensate of lung cancer patients from Puglia Region of Italy. BMC Pulmonary Medicine., 14, 22.

Crawford, JM. (2005) "Liver and Biliary Tract. Pathologic Basis of Disease", Kumar V. et al.(Ed.) Philadelphia". Elsevier Saunders. pp. 924.

Cusumano, V., Costa, G.B. and Seminara, S.( 1990) Effects of aflatoxins on rat peritoneal macrophages. Appl. Environ. Microbiol. 56, 3482-3484.

Dagenais, T.R. and Keller, N.P. (2009) Pathogenesis of Aspergillus fumigatus in invasive aspergillosis". Clin. Microbiol. Rev. 22, 447-465.

De hoog, G.S., Guarro, J., Gene, J. and Figueras, M.J. (2011) "Atlas of Clinical Fungi". Electronic version 3.1. The Netherland; Centraalbureau voor Schimmelcultures.

Denning, D.W. (1998) Invasive aspergillosis, Clin. Infect. Dis. 26,781-803.

Frisvad, J.C. and Thrane, U. (1993) Liquid chromatography of mycotoxins. In: "Chromatography of Mycotoxins. Techniques and Applications" Betina, V. (Ed.), Elsevier, Amsterdam.

Fujie and Akihiko (2007) Discovery of Micafungin (FK463). A novel antifungal derived from a novel product lead .Fermentation Research Laboratoreis, Astellas Pharma Inc.,5-2-6-Tokodai, Tsukuba, Ibaraki 300-2698, Japan.Pure Appl. Chem.79(4),603-614.

Godec, C.J., Mielnick, A. and Hilfer, J. (1989) Primary renal aspergillosis. Urology, 34(3), 152-4.

Gomes, A.M., de Oliveira, D.C. and de Sá, C.P. (2011) The Unified Health System in the users' social representation: An analysis of its structure. Rev Bras Enferm. 64(4), 631-8.

Gonzalez, G.M., Elizondo, M. and Ayala, J. (2008) Trends in species distribution and susceptability to seven antifungal agents of blood stream isolates of Candida in Monterrey, Mexico. Results of a 3-Year (2004-2007). Surverillance Study. J. Clin. Microbiol. 46, 29022905.

Haq, I.U., Lewitt, P.A. and Fernandez, H.H. (2007) Apomorphine therapy in Parkinson's disease: A review. Expert Opin Pharmacother, 8(16), 2799-809.

Egypt. J. Microbiol. 50 (2015) 
Hashimoto, S. (2009) Micafungin: A sulfated echinocandin. J. Antibiot (Tokyo), 62 (1), $27-35$.

Hedayati, M.T., Pasqualotto, A.C., Warn, P.A., Bowyer, P. and Denning, D.W. (2007) Aspergillus flavus: Human pathogen, allergen and mycotoxin producer. Microbiology, 153, 1677-92.

Henderson, A.H., English, M.P. and Veeht, R.J. (1968) Pulmonary aspergillosis: A survey of its occurrence in the patients with chronic lung diseases and a discussion of the significance of diagnostic tests. Thorax. 23, 513-21.

Herbrecht, R., Denning, D., Patterson, T., Bennett, J. and Green, R., et al. (2002) Invasive fungal infections group of the European Organization For Research and Treatment of Cancer and the Golbal Aspergillosis Study Group. Voriconazole versus Amphotercin B for primary therapy of invasive aspergillosis. N. Engl. J. Med. 347(6), 408-415.

Hinton, D.M., Myers, M.J., Raybourne, R.A., Francke-Varroll, S., Sotomayor, R.E., Shaddock, J., Warbritton, A. and Chous, M.W. (2003) Immunotoxicity of aflatoxin B1 in inflammatory response in a chronic intermittent dosing study. Toxicol. Sci. 73, 362-377.

Khan, Z.U., Gopalakrishnan, G., Al-Awadi, K., Gupta, R.K., Moussa, S.A., Chugh, T.D. and Krajci, D. (1995) Renal aspergilloma due to Aspergillus flavus. Clin Infect Dis. 21, 210-212.

Kosalec, I. and Pepeljnjak, S. (2005) Mycotoxigenicity of clinical and environmental Aspergillus fumigatus and A. flavus isolates, Acta Pharm. 20, 365-375.

Kothary, M.H., Chase, T. Jr. and MacMillan, J.D. (1984) Correlation of elastase production by some strains of Aspergillus fumigatus with ability to cause invasive aspergillosis in mice. Infect Immun. 43, 20-5.

Kueter, J.C., MacDiarmi, S.A. and Redman, J.F. (2002) Anuria due to bilateral ureteral obstruction by Aspergillus flavus in an adult male. Urology, 59, 601-609.

Latge, J.P. (1999) Aspergillus fumigatus and aspergillosis, Clin. Microbiol. Rev. 12, 310-350.

Madhavan, P., Jamal, F. and Chong, P. (2011) Laboratory isolation and identification of Candida species. J. Appl. Sci. 11, 2870-2877.

Meersseman, W., Vandecasteele, S.J. and Wilmer, A. (2004) Invasive aspergillosis in critically ill patients without malignancy. Am. J. Respir. Crit. Care. Med. 170, 621-25.

Moon, E.Y., Rhee, D.K. and Pyo, S. (1999) In vitro suppressive effect of aflatoxin B1 on murine peritoneal macrophage functions. Toxicology, 133, 171-179.

Morgan, J., Wannemuehler, K.A., Marr, K.A., Hadley, S., Kontoyiannis, D.P., Walsh, T.J., Fridkin, S.K., Pappas, P.G. and Warnock, D.W. (2005) Incidence of invasive aspergillosis following hematopoietic stem cell and solid organ transplantation: Interim results of a prospective multicenter surveillance program, Med. Mycol. 43, S49-58.

Pappas, P.G., Rotstein, C.M. and Betts, R.F., et al. (2007) Micafungin versus caspofungin for treatment of candidemia and other forms of invasive candidiasis. Clin. Infect. Dis. 1, 45(7), 883-93. 
Patterson, T., Boucher, H., Herbrecht, R., Denning, D., Lortholary, O., Ribaud, P., Rubin, R.H., Wingard, J.R., De Pauw, B., Schlamm, H.T., Troke, P. and Bennett, J.E. (2005) Strategy of following Voriconazole versus amphotericin B therapy with other licensed antifungal therapy for primary treatment of invasive aspergillosis: Impact of other therapies on outcome. Clin. Infect. Dis. 41 (10), 1448-52.

Pepys, J., Riddel, R.W., Citron, K.M., Clayton, Y.M. and Short, E.L. (1959) Clinical and immunological significance of Aspergillus fumigatus in sputum. Am. Rev. Resp. Dis. 80, 167-180 .

Perez-Arellano, J.L., Angel-Moreno, A., Belon, E., Frances, A., Santana, O. E. and MartinSanchez, A.M. (2001) Isolated renoureteric aspergilloma due to Aspergillus flavus: Case report and review of the literature. J. Infect. 42, 163-165.

Pettengell, K., Mynhardt, J and Kluyts, T., et al. (2004) Lau W, Facklam D, Buell D; FK463 South African Study Group.Successful treatment of oesophageal candidiasis by micafungin: A novel systemic antifungal agent. Aliment Pharmacol Ther. 15; 20 (4), 475-81.

Prakash, V., Mishra, P., Verma, S., Sinha, S. and Sharma, M. ( 2014) Prevalence and fungal profile of pulmonary aspergillosis in immunocompromised and immunocompetent patients of a Tertiary Care Hospital. Int. J. Med . Res. Health Sci. 3(1), 92-97.

Ribes, J., Vanover-Sams, C. and Baker, D. (2000) Zygomycetes in human disease. Clin Microbiol. Rev. 13, 236-301.

Shanker, J. ( 2013) An overview of toxins in Aspergillus associated with pathogenesis. Int. J. Life Sci. Bt \& Pharm. Res. 2 (2),18-31.

Shankar, J., Madan, T., Basir, S.F. and Sarma, P.U. (2005) Identification and characterization of polyubiquitin gene from cDNA library of Aspergillus fumigatus. Indian J. Clin. Biochem. 20, 208-212.

Shankar, J., Nigam, S., Saxena, S., Madan, T. and Sarma, P.U. (2004) Identification and assignment of function to the genes of Aspergillus fumigatus expressed at 37 degrees C. $J$. Eukaryote. Microbiol. 51,428-432.

Smith, J. and Safdar, N.K. (2006) Voriconazole therapeutic drug monitoring. Antimicrob Agents Chemother. 50,1570-2.

Smith, J., Safdar, N., Knasinski, V. et al. (2006) Voriconazole therapeutic drug monitoring. Antimicrob Agents Chemother, 50(4),1570-2.

Vandewoude, K.H., Blot, S.I., Depuydt, P., Benoit, D., Temmerman, W. and Colardyn, F. (2006) Clinical relevance of Aspergillus isolation from respiratory tract samples in critically il patients". Crit Care, 10, 31-38.

Warshawsky, R.S., Hill, C.W., Doughman, D.J. and Harris, J.E. (1975) Acrodermatitis enteropathica. Corneal involvement with histochemical and electron micrographic studies". Arch Ophthalmol. 93(3),194-7. 
White, T.B., Runs, T., Lee, S. and Taylor, J. (1990) Amplification and direct sequencing of ungal ribososmal RNA enes for phylogenetics. In: Innis, M, Gelfand, D. Sninsk,y J. White, T., Ed. PCR Proto-cols. New York, NY: Academic Press, Inc. pp. 315-322.

Willems, L., van der Geest, R. and de Beule, K.( 2001) Itraconazole oral solution and intravenous formulations: A review of pharmacokinetics and pharmacodynamics. J. Clin. Pharm. Ther. 26,159-69.
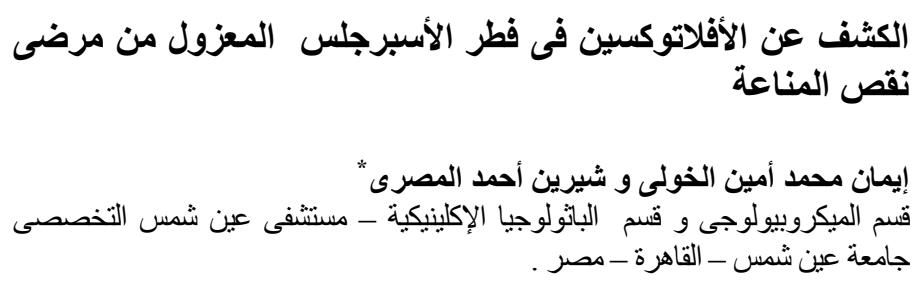

ازدادت اهميه عدوى الرشاشيات في السنوات الأخيرة. ومع ذلك ، الإنير إنان معظم

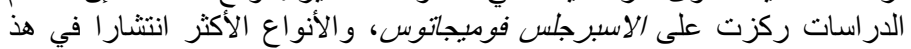

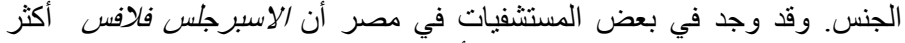

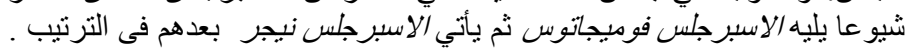

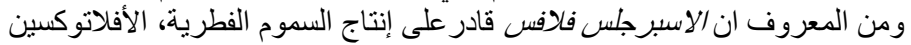

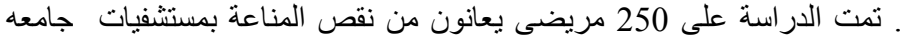

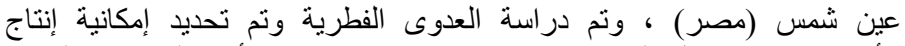

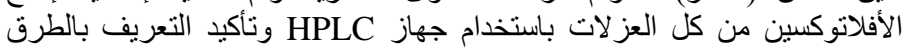

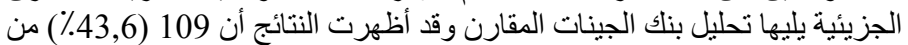

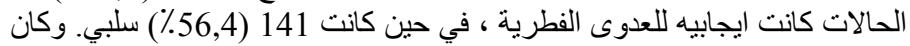

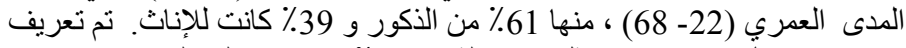

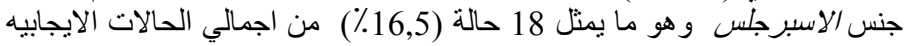

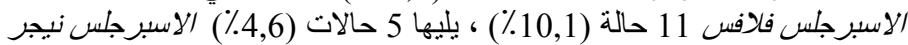

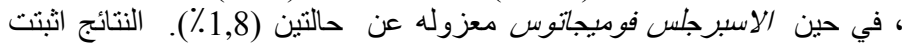

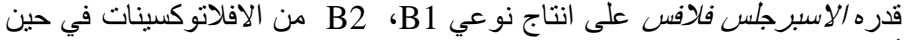

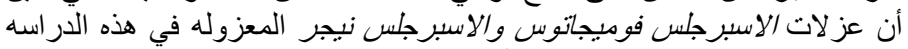

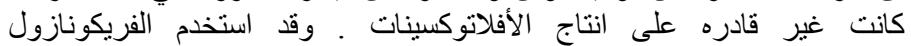
والميكافنجين بنجاح في علاج جميع الحالات. 